\title{
Medically treated suicide attempts: a four year monitoring study of the epidemiology in The Netherlands
}

\author{
E Arensman, A J F M Kerkhof, $M$ W Hengeveld, J D Mulder
}

\begin{abstract}
Objective - The incidence of medically treated attempted suicides was investigated in a defined area in the western part of The Netherlands, and demographic groups at risk were identified.

Data and methods - Suicide attempts treated at general hospitals, psychiatric hospitals, and in general practice were monitored between 1 January 1989 and 1 January 1993. Information on demographic characteristics of the subjects who attempted suicide and characteristics of the attempts was registered through a monitoring system and there was maximum coverage. Data on the general population in the catchment area were derived from national, regional, and municipal bureaux of statistics.
\end{abstract}

Results - The mean annual incidences of medically treated suicide attempts (events) were 95/100 000 for males and 155 I 100000 for females. At risk groups for attempted suicide were the young $(<40$ years); females; people who were divorced, unemployed, or disabled; or those who had low levels of education.

Conclusions - Apart from general hospitals and psychiatric hospitals, $28 \%$ of all reported suicide attempts were reported exclusively by general practitioners, which supports the conclusion that they are an important source of information. There were indications that the number of medically treated suicide attempts in this area is stabilising.

Clinical,

Health and Personality

Psychology,

Leiden University,

PO Box 9555,

2300 RB Leiden,

The Netherlands

E Arensman

A J F M Kerkhof

Department of Psychiatry, Leiden University, PO Box 9600, 2300 RC Leiden,

The Netherlands

$M W$ Hengeveld

Department of Family Medicine,

Leiden University,

PO Box 2088,

2301 CB Leiden,

The Netherlands

J D Mulder

Correspondence to:

Dr E Arensman.

Accepted for publication November 1995 acteristics of patients treated only in emergency wards, or those looked after exclusively by general practitioners (GPs). Moreover, the characteristics of people who attempt suicide are rarely related to the characteristics of the population in the area under study.

This study aimed to monitor medically treated suicide attempts in a defined catchment area, to estimate the true incidence, to identify demographic groups at risk, and to investigate repeat episodes.

\section{Methods}

Data were gathered from general hospitals, psychiatric hospitals, and GPs. During 198992, participants were asked to report all suicide attempts ${ }^{2}$ that came to their attention, even if they did not personally treat the patient. With regard to terminology, "attempted suicide" will be used interchangeably with "parasuicide" to mean "an act with non-fatal outcome in which an individual deliberately initiates a non-habitual behaviour that, without intervention from others, will cause self-harm, or ingests a substance in excess of the prescribed or generally recognized dosage, and which is aimed at realizing changes that the person desires via the actual or expected physical consequences". ${ }^{8}$ Monitoring forms were obtained every month from each psychiatric hospital, and every two months from each GP. Information on suicide attempts treated at general hospitals was registered on monitoring forms by psychiatric residents, and by the researchers. The monitoring form was used to collect data on age, sex, marital status, household composition, education, economic situation, religious denomination, and characteristics of suicidal behaviour, such as the method, and repetition after the index attempt. The study was approved by the ethics committee of the Leiden University Hospital, and information concerning persons who had attempted suicide was treated under strict conditions of confidentiality.

Between 1 January 1989 and 1 January 1990, all three general hospitals in the catchment area participated. From 1 January 1990 to 31 December 1992, two small general hospitals were excluded from the study, because only $2 \%$ of all suicide attempts were treated there. The completeness of reported suicide attempts was verified in different ways. Each week from 1 October 1990 to 31 December 1992 the researchers checked the registration of suicide attempts treated at the emergency and surgical wards of the University Hospital. It seemed 
that not all attempted suicides were reported because of practical problems such as time pressure and replacement of members of the medical staff. It was estimated that in 1989, $65 \%$ of all suicide attempts treated in a general hospital were reported. After intensified control of the registration by the researchers, however, it was estimated that in 1990,1991 , and 1992 data were obtained on $80 \%, 95 \%$, and $95 \%$ respectively of all hospital treated suicide attempts.

In $1989,75 \%$ of all 135 GPs in the catchment area participated in the study, in 1990-92, $70 \%, 65 \%$, and $65 \%$ respectively participated. The registration of suicide attempts by GPs became more complete, due to more intensive control. Incomplete data were checked by telephoning the GPs. It was estimated that the reported percentages of suicide attempts treated in general practice in the catchment area were $50 \%$ in $1989,65 \%$ in 1990 and 1991 , and $60 \%$ in 1992 .

In 1989 and 1990 all three psychiatric hospitals, and in the last three years, two psychiatric hospitals participated. It was estimated that the reported percentages of suicide attempts treated in psychiatric hospitals were $50 \%$ in $1989,45 \%$ in 1990 and 1991 , and $40 \%$ in 1992. On the basis of non-participation and non-response, it was estimated that the percentage of reported suicide attempts in the entire four year period amounted to $70 \%$ of all medically treated suicide attempts in the catchment area.

The accuracy of the registration by the agencies could be evaluated for the period October 1990 to December 1991. Of all those who attempted suicide in this period and who were treated in the University Hospital, $65 \%$ were also interviewed personally in connection with a repetition prediction study. Furthermore, $15 \%$ of the suicide attempts were reported by two or more agencies. Discrepancy in the information was found in less than $5 \%$ of all cases.

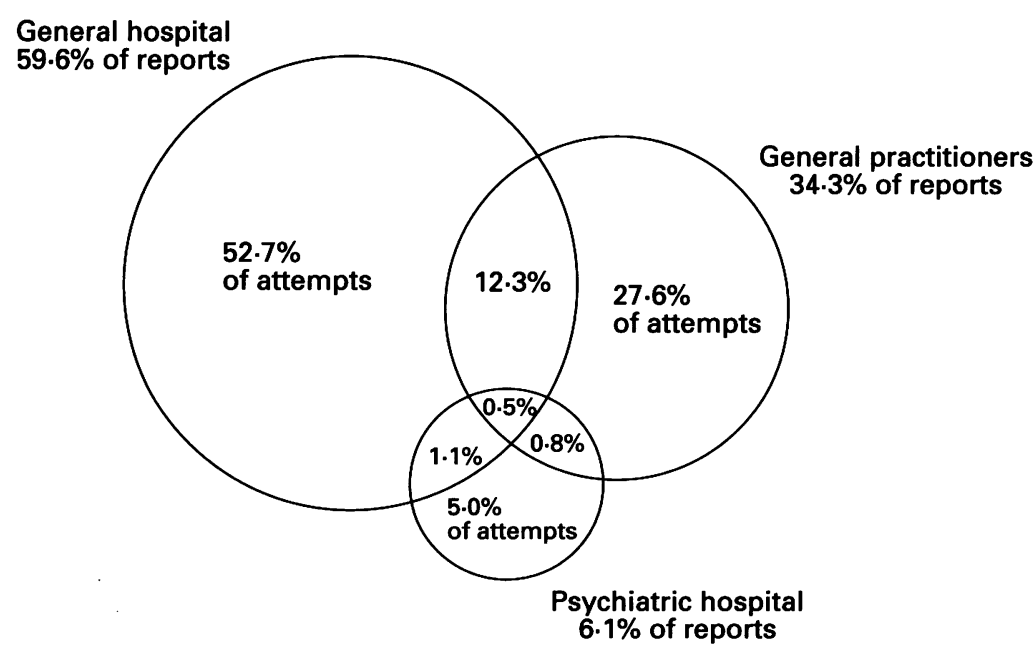

Total number of reports: $\mathbf{8 7 5}$

Total number of suicide attemps (events): 793

Figure 1 Distribution of reported suicide attempts by participating persons and agencies, 1989-92.
The data were statistically analysed by $\chi^{2}$ test, $t$ test, and ANOVA. Demographic characteristics of the catchment area have been described previously. ${ }^{1011}$ With regard to the demographic variables included in the study, no differences were found between the catchment area and The Netherlands as a whole. ${ }^{11}$

In a previous publication, a comparison was made between all research centres from the WHO/EURO multicentre study regarding attempted suicide rates in relation to age and sex. ${ }^{8}$ No results were presented on demographic characteristics of those who attempted suicide compared with the general population.

\section{Results}

The distribution of suicide attempts reported through monitoring forms is presented in figure 1. Due to double reporting of some of the events, the number of monitoring forms $(n=$ 875 ) was higher than the actual number of suicide attempts $(n=793)$. With regard to the total number of identified suicide attempts, $66.6 \%$ were reported by the general hospitals while $41 \cdot 2 \%$ were reported by GPs. Of all suicide attempts, $7 \cdot 4 \%$ were identified by psychiatric hospitals. In $52.7 \%$ of the cases the general hospital, and in $27.6 \%$ of the cases the GP was the only reporting agency. The mean annual number of suicide attempts treated by each GP was $2 \cdot 3$. Of all suicide attempts reported by two or more agencies, the highest overlap was found between general hospitals and GPs: $12 \cdot 3 \%$ were reported by both GPs and general hospitals.

During the period 1989-92, completed monitoring forms were collected on 793 suicide attempts (events), which involved 690 persons. The total number of reports comprised 1166 suicide attempts (events). Table 1 presents the number of suicide attempts reported by all participating persons and the estimated number of actual suicide attempts, which was arrived at by means of extrapolation from the available information. Through extrapolation, annual person and event rates per 100000 population were calculated. The estimation factor was calculated on the basis of the estimated annual percentage of reported suicide attempts by all participating agencies: 1989: 100/66= 1.52 ; 1990 : $100 / 73=1 \cdot 36 ; 1991$ : $100 / 82=$ $1 \cdot 22 ; 1992: 100 / 79=1 \cdot 26$. The formula for extrapolation is the estimation factor $\times$ the reported number of suicide attempts. For example data on 1989: persons 1989:

Table 1 The number of reported suicide attempts, the number of suicide attempts after extrapolation, and suicide attempt rates per 100000 population (persons and events), 1989-92

\begin{tabular}{lllll}
\hline & 1989 & 1990 & 1991 & 1992 \\
\hline $\begin{array}{l}\text { Reported suicide attempts: } \\
\quad \text { Persons }\end{array}$ & 214 & 261 & 257 & 255 \\
$\quad \begin{array}{lll}\text { Events } \\
\text { After extrapolation: }\end{array}$ & 248 & 301 & 326 & 291 \\
$\quad$ Persons & 325 & 355 & 313 & 321 \\
$\quad$ Events & 377 & 409 & 398 & 367 \\
$\begin{array}{l}\text { Rates per 100 000: } \\
\quad \text { Persons }\end{array}$ & 111 & 120 & 105 & 107 \\
$\quad$ Events & 128 & 138 & 133 & 121 \\
Estimation factor & 1.52 & 1.36 & 1.22 & 1.26 \\
\hline & & & &
\end{tabular}




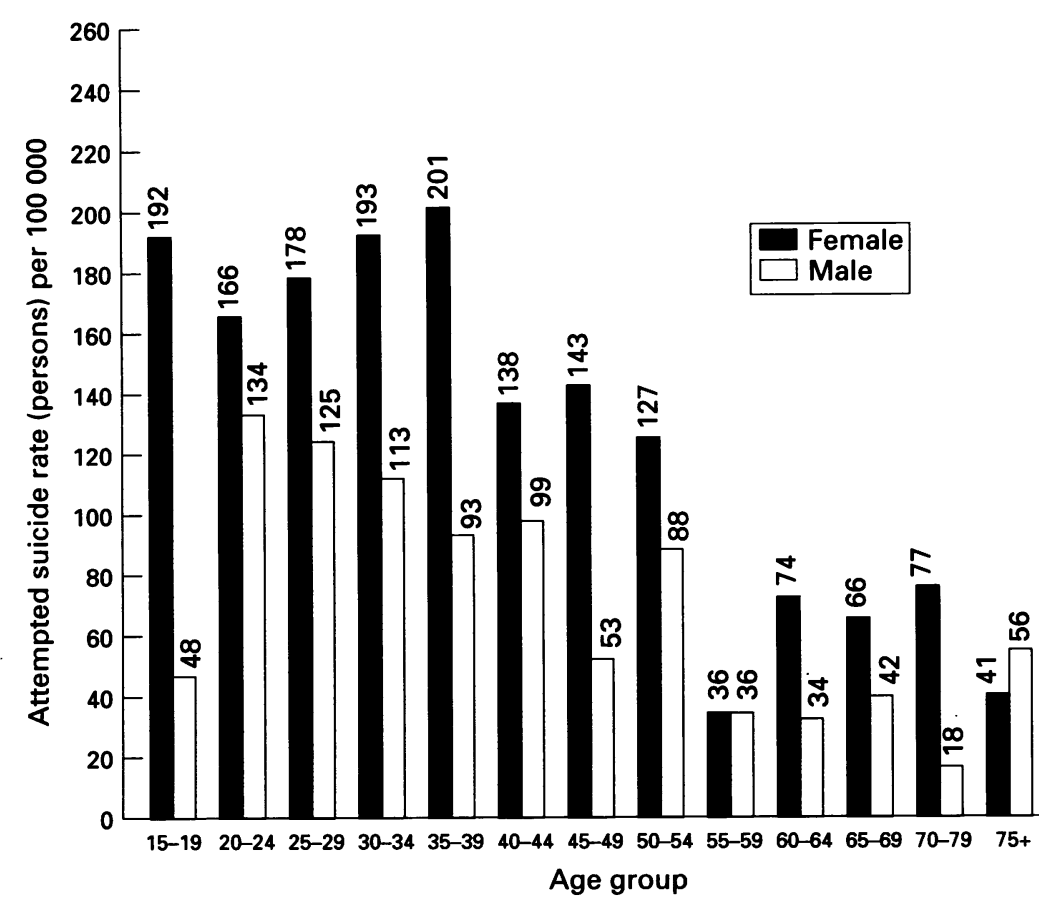

Figure 2 Mean annual age-specific attempted suicide (person) rates per 100000 population in relation to sex, 1989-92.

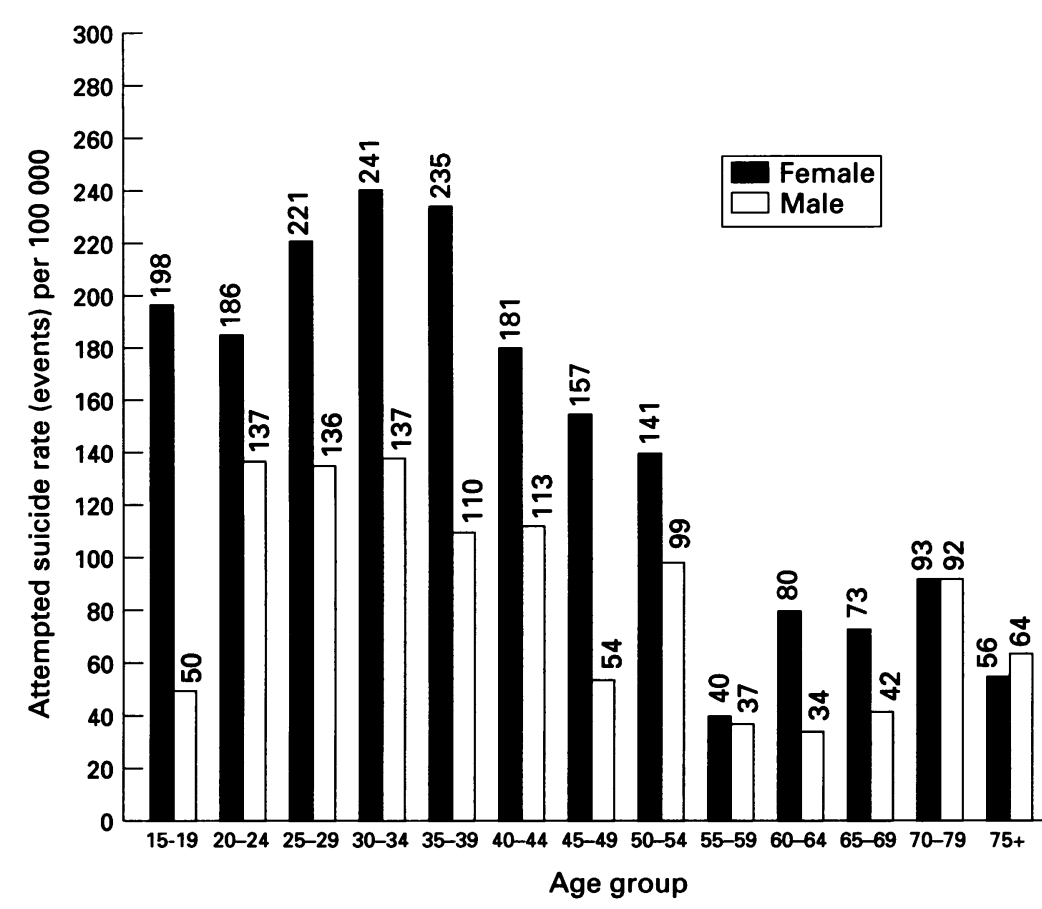

Figure 3 Mean annual age-specific attempted suicide (event) rates per 100000 population in relation to sex, 1989-92. annual person rate for men was $85 / 100000$, and for women this was $139 / 100000$. The mean annual event rates for men and women were respectively $95 / 100000$ and $155 / 100000$. The ratio of female:male (person) rates for persons was 1.64. No difference was found between the mean (SD) age of women $(35 \cdot 8(14 \cdot 1))$ and of men $(36 \cdot 1(15 \cdot 4))$.

With regard to marital status, the highest mean annual attempted suicide rates for both men (191/100 000) and women (248/100 000) were found in divorced people, with higher rates among women. The lowest rates for both men (16/100 000) and women (39/100 000) were found among widowed people.

Table 2 presents suicide attempts (persons) in relation to the level of education and sex. Compared with the general population, those with low levels of education were significantly over-represented among those who attempted suicide. There were no significant differences between men and women.

Suicide attempts (persons) in relation to employment status and sex are presented in table 3. Compared with the general population, those who attempted suicide were significantly more likely to be unemployed and disabled; and this was true for both men and women. The highest attempted suicide rates were found in the unemployed, with higher rates in women than men. Unemployment was defined as "the number of people looking for work as a percentage of the dependent labour force".

On a number of demographic variables, no significant differences were found between the sample and the general population. These were household composition, religious denomination, mobility, country of birth, and nationality.

\section{CHARACTERISTICS OF SUICIDAL BEHAVIOUR}

Repetition can be calculated in different ways - depending on the time perspective (retrospective or prospective), depending on the time span (within a maximum period of 48 months), and depending on the source of information (monitoring forms or reports). From a retrospective point of view, it seemed that at least $50.7 \%$ of all persons had attempted suicide before and $21.6 \%$ had done so within the last 12 months. From a prospective point of view, it seemed that at least $11 \%$ made a repeat attempt within 12 months, and $14 \%$ repeated within 24 months. After 36 months, $16 \%$ had repeated and after $\mathbf{4 8}$ months this figure was $17 \%$. Taking into account non-response, it was estimated that the actual percentage who repeated an attempt within the four years was at least $25 \%$. Of all persons who repeated an attempt within the study period $(n=97)$, most $(73 \%)$ did so within 12 months after the index suicide attempt. Among those who were making a repeat attempt at the time of the index suicide attempt, at least $27 \cdot 3 \%$ repeated once or more than once within the four year period. This is significantly higher than the $10 \cdot 1 \%$ of the persons who were making first ever attempts at the time of the index suicide attempt $\left(\chi^{2}=\right.$ $9 \cdot 72, \mathrm{df}=1, \mathrm{p}<0.001$ ). 
Table 2 Level of education in relation to sex, in the sample and in the general population aged 15-64 years, 1989-92 (mean)

\begin{tabular}{|c|c|c|c|c|c|c|}
\hline Level of education & $\begin{array}{l}\text { Males sample } \\
(\%)\end{array}$ & $\begin{array}{l}\text { Females sample } \\
(\%)\end{array}$ & $\begin{array}{l}\text { Total sample } \\
(\%)\end{array}$ & $\begin{array}{l}\text { Total general } \\
\text { population } \dagger \\
(\%)\end{array}$ & $\begin{array}{l}\text { Samplel } \\
\text { general } \\
\text { population } \dagger \\
\chi^{2}\end{array}$ & $\begin{array}{l}\text { Total attempted } \\
\text { suicide ratel } \\
100000\end{array}$ \\
\hline \multirow{4}{*}{$\begin{array}{l}\text { Primary school/special } \\
\text { lower education } \\
\text { Lower vocational } \\
\text { training/lower } \\
\text { secondary education } \\
\text { Middle secondary } \\
\text { education/higher } \\
\text { secondary education/ } \\
\text { middle vocational } \\
\text { training } \\
\text { Higher vocational } \\
\text { training/university }\end{array}$} & $23 \cdot 7$ & $29 \cdot 3$ & $27 \cdot 3$ & $11 \cdot 5$ & $7 \cdot 94^{*}$ & 160 \\
\hline & $43 \cdot 8$ & $42 \cdot 6$ & $43 \cdot 0$ & $18 \cdot 3$ & $14 \cdot 40^{* *}$ & 157 \\
\hline & $17 \cdot 0$ & $20 \cdot 1$ & $19 \cdot 0$ & $44 \cdot 9$ & $15 \cdot 42^{* *}$ & 29 \\
\hline & $15 \cdot 5$ & $8 \cdot 0$ & $10 \cdot 7$ & $25 \cdot 3$ & $7 \cdot 22^{*}$ & 27 \\
\hline Total no & 186 & 316 & 502 & 74830 & & \\
\hline
\end{tabular}

${ }^{*} p<0.01 ;{ }^{* *} p<0.001$; missing values: $n=143$; persons $65+: n=45$

t General population in the catchment area.

Table 3 Employment status in relation to sex in sample and the general population $1989-92$ (mean)

\begin{tabular}{|c|c|c|c|c|c|c|}
\hline & $\begin{array}{l}\text { Males sample } \\
(\%)\end{array}$ & $\begin{array}{l}\text { Males gen popt } \\
(\%)\end{array}$ & $\begin{array}{l}\text { Male } \\
\text { parasuicide ratel } \\
100000\end{array}$ & $\begin{array}{l}\text { Females } \\
\text { sample } \\
(\%)\end{array}$ & $\begin{array}{l}\text { Females } \\
\text { gen popt } \\
(\%)\end{array}$ & $\begin{array}{l}\text { Female } \\
\text { attempted } \\
\text { suicide ratel } \\
100000\end{array}$ \\
\hline $\begin{array}{l}\text { Employed } \\
\text { Unemployed } \\
\text { Disabled } \\
\text { Other }\end{array}$ & $\begin{array}{l}45 \cdot 5 \\
22 \cdot 1 \\
20 \cdot 0 \\
12 \cdot 4\end{array}$ & $\begin{array}{c}67 \cdot 3^{* * * *} \ddagger \\
2 \cdot 8^{* * * *} \\
7 \cdot 2^{* *} \\
22 \cdot 7^{*}\end{array}$ & $\begin{array}{r}27 \ddagger \\
322 \ddagger \\
1139 \\
22 \rrbracket\end{array}$ & $\begin{array}{l}22 \cdot 8 \\
15 \cdot 1 \\
11 \cdot 1 \\
51 \cdot 0\end{array}$ & $\begin{array}{c}49 \cdot 1^{* * *} \\
2 \cdot 2^{* * *} \\
3 \cdot 6^{*} \\
45 \cdot 1\end{array}$ & $\begin{array}{r}31 \ddagger \\
455 \ddagger \\
205 \oint \\
759\end{array}$ \\
\hline Total no & 235 & 577226 & & 404 & 610107 & \\
\hline
\end{tabular}

Missing values; $\mathrm{n}=51$

+ Gen pop = general population in the catchment area.

‡Attempted suicide rates per 100000 economically active population aged 15-64 years.

SAttempted suicide rates per 100000 disabled population aged 15-64 years.

I Attempted suicide rates per 100000 economically inactive population aged $15+$

$\chi^{2}$ test: males sample/males general population, females sample/females general population.

${ }_{\mathrm{p}<0.05 ;{ }^{* *} \mathrm{p}<0.01 ;{ }^{* * *} \mathrm{p}<0 \cdot 001 \text {. }}$.

Most (76\%) ingested medicines as the method of the index attempt, and among these more than two thirds ingested minor tranquillisers and sedatives. No differences were found between men and women in this respect.

A comparison was made between suicide attempts (events), which were treated in a general hospital $(n=648)$ and those treated exclusively by GPs $(n=114)$. No differences were found in terms of demographic characteristics. With respect to characteristics of suicidal behaviour only one significant difference was found. People treated in a general hospital after attempted suicide were more often repeaters $(59 \cdot 1 \%)$ than those treated by GPs $(41 \cdot 7 \%)$ $\left(\chi^{2}=6 \cdot 05, \mathrm{df}=1, \mathrm{p}<0 \cdot 01\right)$

\section{Discussion}

In order to obtain a picture of medically treated suicide attempts, it is important not to rely on information from general and psychiatric hospitals, but to collect data on suicide attempts treated in general practice as well. An important finding of this study was that $28 \%$ of all reported suicide attempts were reported exclusively by GPs.

It is important with a rare phenomenon to have a minimum of missing cases. That is why the WHO/EURO multicentre study was designed so that maximum coverage could be realised. The true incidence of medically treated suicide attempts was estimated taking into consideration non-response and missing information from participating agencies. For the entire period $1989-92,70 \%$ of all medically treated suicide attempts in the area of Leiden were reported by the participating agencies. This overall finding of $70 \%$ response was confirmed by different sources of information. Firstly, the percentage of participating and nonparticipating persons and agencies, and the completeness of the registration was painstakingly checked. A second source for checking the validity of the response is the official data on the number of suicides in the catchment area. The participating agencies reported cases of suicide as well. Compared with the official data, $66 \%$ of all suicides were reported by the participating persons and agencies, thus confirming the estimated response of suicide attempts. From this study it seemed that in areas where GPs treat suicide attempts independently from general hospitals, a maximum response of about $70 \%$ accuracy in monitoring research can be achieved.

The incidence of medically treated suicide attempts in the area of Leiden showed a stable pattern during the four year period. It is difficult to compare these rates with the incidence of medically treated suicide attempts in the beginning of the $1980 \mathrm{~s}$, because no data are available for the catchment area. Hospital records from 1983, however, show numbers of attempts treated to be comparable with those in 1989-92. ${ }^{13}$ Compared with other European research centres participating in the WHO/ EURO multicentre study on parasuicide, the rates in the area of Leiden are relatively low. ${ }^{89}$

In calculating suicide attempt rates we excluded 86 people who lived outside the catchment area. If we take into account those who 
lived in the catchment area, but who may have been treated for attempted suicide in a health facility outside the catchment area (assuming this will be about the same as the number of persons we excluded) the mean rate of suicide attempts (events) would be 143 per 100000 population, which is still low compared with other regions in Europe.

With respect to demographic characteristics, the results showed that attempted suicide was commonly found in women and in those aged 15-39 years, which is in line with findings of other studies. ${ }^{256}$ Persons who attempted suicide were significantly more often divorced, unemployed, disabled, and had low levels of education. From this study we learned that it would not be feasible to integrate the registration of suicide attempts in the daily work of health care professionals. It is only possible to achieve a response of about $70 \%$ where there is sufficient manpower to provide the information that is required, verify the validity of the registration, and motivate the participating agencies to continue.

This study is part of the WHO/EURO multicentre study on parasuicide in which 14 centres in 12 European countries parasuicide in which 14 centres in 12 European countries participate.
by the publication committee.
We are grateful to the general practitioners, the general hospitals, and the psychiatric hospitals in the area of Leiden for providing the data during the four year study period. We thank Dr C J Verduin for assistance during data analysis and Dr L T Sweeney who helped with the English text.

1 Weissman MM. The epidemiology of suicide attempts, 1960 to 1971. Arch Gen Psychiatry 1974;30:737-46.

y: London 1977

3 Wexler L, Weissman MM, Kasl SV. Suicide attempts 1970 75: Updating a United States study and comparisons with international trends. Br $\mathfrak{F}$ Psychiatr 1978;132:180-5.

4 Diekstra RFW. Suicide and suicide attempts in the European Economic Community: An analysis of trends, with specia emphasis upon trends among the young. Suicide Life Threat Behav 1985;15:402-21.

5 Hawton K, Fagg J. Trends in deliberate self poisoning and self injury in Oxford, 1976-90. BMF 1992;304:1409-11.

6 Platt S, Hawton K, Kreitman N, Fagg J, Foster J. Recent clinical and epidemiological trends in parasuicide in $\mathrm{Ed}$ clinical and epidemiological trends in parasuicide in $\mathrm{Ed}$ 1988;18:405-18.

7 Diekstra RFW. The epidemiology of suicide and parasuicide. Acta Psychiatr Scand 1993;Suppl 371:9-20.

8 Platt S, Bille-Brahe U, Kerkhof A, et al. Parasuicide in Europe: the WHO/EURO multicentre study on parasuicide. I. Introduction and preliminary analysis for 1989 Acta Psychiatr Scand 1992;85:97-104.

9 Schmidtke A, Bille-Brahe U, Kerkhof A, et al. The WHO/ EURO multicentre project on parasuicide - state of the art. Italian fournal of Suicidology 1993;3:83-95.

10 Bille-Brahe U. Facts and figures: WHO/EURO multicentre study on parasuicide. Copenhagen: WHO Regional Office for Europe, 1993.

11 Kerkhof AJFM, Bernasco W. WHO/EURO multicentre study on parasuicide: Progress report no 1. Leiden: Department
of Clinical, Health and Personality Psychology, Leiden University: 1988.

12 Central Statistics Bureau (CBS). Enquete beroepsbevolking 1989-1992. 's-Gravenhage: Staatsuitgeverii, 1993.

13 Kerkhof AJFM. Suicide en de geestelijke gezondheidszorg. Dissertation. Lisse: Swets \& Zeitlinger, 1985. 